\title{
Estimasi Deplesi Lingkungan Subsektor Kehutanan di Jawa Timur
}

\author{
Laksmita Dwi Hersaputri dan Eko Budi Santoso \\ Departemen Perencanaan Wilayah dan Kota, Fakultas Teknik Sipil dan Perencanaan, Institut \\ Teknologi Sepuluh Nopember (ITS) \\ e-mail:eko_budi@urplan.its.ac.id
}

\begin{abstract}
Abstrak-Perekonomian Jawa Timur yang salah satunya ditopang oleh subsektor kehutanan, belum terjamin akan seterusnya berlanjut sampai jangka panjang, karena aktivitas ekonomi tidak selalu berbanding lurus dengan kondisi lingkungan hidup. Subsektor kehutanan memiliki nilai jasa lingkungan yang tinggi dalam meminimalkan perubahan iklim dan pemanasan global bagi kesejahteraan manusia. Namun hutan di Jawa Timur mengalami degradasi lingkungan setiap tahunnya akibat kegiatan ekonomi yang turut memanfaatkan kekayaan alam hutan, yang salah satunya berupa deforestasi atau aktivitas penebangan. Sehingga, diperlukan adanya perhitungan deplesi lingkungan guna mengetahui kontribusi subsektor kehutanan yang sebenarnya, yaitu mempertimbangkan aspek lingkungan. Deplesi merupakan penyusutan karena penggunaan sumber daya alam yang dieksploitasi sehingga semakin lama semakin menipis. Hasil dari estimasi deplesi dapat digunakan sebagai input data dalam perhitungan PDRB Hijau dan pertimbangan kebijakan mengenai pemanfaatan sumber daya hutan. Metode pengumpulan data dilakukan cara survei instansional yaitu memperoleh data-data dari instansi terkait yang dibutuhkan dan sesuai dengan variabel penelitian. Data tersebut kemudian dianalisis dengan perhitungan matematis menggunakan rumus deplesi. Dari analisis yang telah dilakukan, didapatkan hasil akhir berupa nilai deplesi lingkungan di Jawa Timur yaitu sebesar Rp 1,46 Triliun. Dimana nilai deplesi di setiap kabupaten di Jawa Timur pada tahun 2011-2015 yang terbesar terdapat di Kabupaten Pacitan yaitu sebesar Rp 454 Miliar, sementara deplesi terendah terdapat di Kabupaten Pamekasan yaitu sebesar Rp 58 Juta.
\end{abstract}

Kata Kunci-Deplesi Lingkungan, Kehutanan, Penyusutan.

\section{PENDAHULUAN}

$\mathrm{P}$ ILAR pembangunan di Provinsi Jawa Timur bertumpu pada pro-keadilan, pro-pertumbuhan ekonomi, dan prolingkungan dengan dukungan kebijakan penataan ruang yang konsisten [1]. Pernyataan tersebut menunjukkan bahwa Jawa Timur turut memasukkan aspek lingkungan dalam perencanaan pembangunannya. Selain itu, menurut Rencana Aksi Daerah untuk Penurunan Emisi Gas Rumah Kaca (RAD-GRK) sebagai salah satu upaya adaptasi dan mitigasi perubahan iklim, direncanakan program dalam rangka menurunkan GRK di Jawa Timur, yakni melalui sektor kehutanan, pertanian, energi, transportasi, perindustrian, dan pengelolaan limbah [2].

Provinsi Jawa Timur memiliki luas hutan terbesar diantara provinsi lainnya, yaitu seluas 1.361.146 Ha atau sekitar 41,1\% dari seluruh luas hutan di Pulau Jawa [3]. Namun, Jawa Timur merupakan penyumbang terbesar terjadinya deforestasi (penebangan hutan) di Pulau Jawa, yaitu sebesar 438,1 Ha per tahun [4]. Deforestasi tersebut disebabkan oleh berbagai kegiatan seperti penebangan liar, kebakaran hutan yang kerap terjadi, serta penebangan guna memenuhi kebutuhan masyarakat akan kayu [5]. Padahal, hutan memiliki nilai jasa yang jauh lebih besar dibandingkan dengan nilai kayu. Diperkirakan nilai kayu hanya sekitar $15 \%$ dari total nilai ekonomi hutan [6]. Dampak yang ditimbulkan adalah bencana banjir yang secara rutin menimpa wilayah Jawa Timur, demikian pula dengan bencana tanah longsor, serta kebakaran hutan di musim kemarau [7].

Berdasarkan pemaparan masalah diatas, diperlukan adanya perhitungan mengenai deplesi lingkungan yang terjadi di subsektor kehutanan. Deplesi atau penyusutan merupakan suatu cara pengambilan sumber daya alam secara besarbesaran, yang biasanya demi memenuhi akan bahan-bahan mentah. Deplesi dapat juga diartikan sebagai pengurasan sumber daya alam, yaitu sumber daya yang walaupun dapat diimbangi dengan usaha konservasi, namun dampaknya terhadap lingkungan hidup masih akan membekas dan membutuhkan waktu lama untuk pemulihannya [8]. Deplesi sumber daya hutan itu sendiri merupakan pengurangan jumlah sumber daya hutan yang disebabkan oleh faktor ekonomi dan non-ekonomi. Deplesi ditentukan dari beberapa indikator, yaitu deplesi wilayah kehutanan, deplesi hutan, dan nilai kayu tebangan. Deplesi hutan memiliki variabel yaitu deplesi hutan kaarena kebakaran, penyakit, bencana alam, binatang, serta berkurangnya nilai tanah karena degradasi ekonomi hutan. Nilai kayu tebangan memiliki variabel yaitu harga kayu, volume kayu, serta nilai kayu [9].

Perhitungan deplesi lingkungan ini diharapkan dapat menjadi studi awal dari perhitungan PDRB hijau subsektor kehutanan, yaitu perhitungan PDRB yang telah memasukkan unsur lingkungan di dalamnya, agar menghindari nilai PDRB yang meningkat tetapi pada kenyataannya susut modal alami lebih besar daripada nilai tambah yang diciptakan.

\section{METODE PENELITIAN}

\section{A. Jenis dan Pendekatan Penelitian}

Pendekatan yang digunakan dalam penelitian ini adalah pendekatan positivistik. Penelitian yang memiliki dasar positivistik merupakan penelitian yang menekankan penggunaan metode statistik untuk mencari jawaban permasalahan yang hendak diteliti [10]. Jenis penelitian dalam 
penelitian ini adalah deskriptif kuantitatif.

\section{B. Variabel Penelitian}

Variabel penelitian yang digunakan untuk mengestimasi nilai deplesi lingkungan subsektor kehutanan di Jawa Timur adalah jenis kayu yang ditebang, volume kayu yang ditebang, harga jual kayu, biaya produksi kayu, serta suku bunga.

C. Mengestimasi Nilai Deplesi Lingkungan Subsektor Kehutanan di Jawa Timur

Deplesi lingkungan merupakan kuantifikasi kuantitas sumber daya hutan yang terdeplesi dan dihitung nilai ekonominya. Estimasi nilai deplesi lingkungan subsektor kehutanan dilakukan dengan menggunakan rumus sistematis deplesi lingkungan [11], yaitu:

\section{Deplesi $=V p k \times N r k$}

Dimana $V p k$ adalah volume produksi kayu, dan $N r k$ adalah nilai unit rent kayu.

$$
N r k=H i-B i-L i
$$

Dimana $H i$ adalah harga per unit kayu, $B i$ adalah biaya produksi per unit kayu, dan $L i$ adalah laba layak atau balas jasa investasi (yang diasumsikan dengan suku bunga Bank Indonesia).

\section{HASIL DAN DISKUSI}

\section{A. Estimasi Nilai Deplesi Lingkungan Subsektor Kehutanan di Jawa Timur}

Deplesi lingkungan menggambarkan valuasi ekonomi dari sumber daya alam yang digunakan oleh subsektor kehutanan pada kegiatan ekonomi. Pada penelitian ini, deplesi lingkungan menggambarkan valusi ekonomi dari sumber daya hutan yang hilang berupa kayu jati dan kayu rimba yang digunakan untuk menunjang kegiatan ekonomi. Deplesi lingkungan yang akan diestimasi pada penelitian ini merupakan deplesi dalam kurun 5 tahun, yaitu dari tahun 2011-2015.

Tabel 1.

Estimasi Deplesi Lingkungan Subsektor Kehutanan di Jawa Timur tahun 2015 (Rp.)

\begin{tabular}{|c|c|c|}
\hline No. & Kabupaten & Nilai Deplesi \\
\hline 1. & Kab. Pacitan & 454.638 .764 .676 \\
\hline 2. & Kab. Ponorogo & 108.914 .556 .478 \\
\hline 3. & Kab. Trenggalek & 200.129 .464 .274 \\
\hline 4. & Kab. Tulungagung & 17.533 .866 .234 \\
\hline 5. & Kab. Blitar & 24.971 .887 .844 \\
\hline 6. & Kab. Kediri & 47.045 .039 .549 \\
\hline 7. & Kab. Malang & 14.283 .212 .079 \\
\hline 8. & Kab. Lumajang & 3.902 .142 .907 \\
\hline 9. & Kab. Jember & 111.093 .378 .465 \\
\hline 10. & Kab. Banyuwangi & 183.540 .312 .262 \\
\hline 11. & Kab. Bondowoso & 37.836 .229 .896 \\
\hline 12. & Kab. Situbondo & 5.072 .699 .520 \\
\hline 13. & Kab. Probolinggo & 12.215 .514 .085 \\
\hline 14. & Kab. Pasuruan & 2.363 .968 .128 \\
\hline 15. & Kab. Mojokerto & 3.084.797.956 \\
\hline 16. & Kab. Jombang & 605.998 .479 \\
\hline 17. & Kab. Nganjuk & 21.973 .435 .114 \\
\hline 18. & Kab. Madiun & 77.513 .338 .655 \\
\hline 19. & Kab. Magetan & 3.821 .626 .988 \\
\hline 20. & Kab. Ngawi & 49.223 .227 .411 \\
\hline 21. & Kab. Bojonegoro & 34.637 .838 .446 \\
\hline
\end{tabular}

\begin{tabular}{llc}
\hline \hline No. & \multicolumn{1}{c}{ Kabupaten } & Nilai Deplesi \\
\hline 22. & Kab. Tuban & 31.272 .436 .597 \\
23. & Kab. Lamongan & 2.310 .130 .306 \\
24. & Kab. Gresik & 515.972 .917 \\
25. & Kab. Bangkalan & 3.291 .975 .966 \\
26. & Kab. Sampang & 3.836 .461 .607 \\
27. & Kab. Pamekasan & 58.209 .226 \\
28. & Kab. Sumenep & 2.858 .419 .317 \\
TOTAL & 1.458 .544 .905 .384 \\
\hline \hline
\end{tabular}

Sumber: Penulis, 2017.

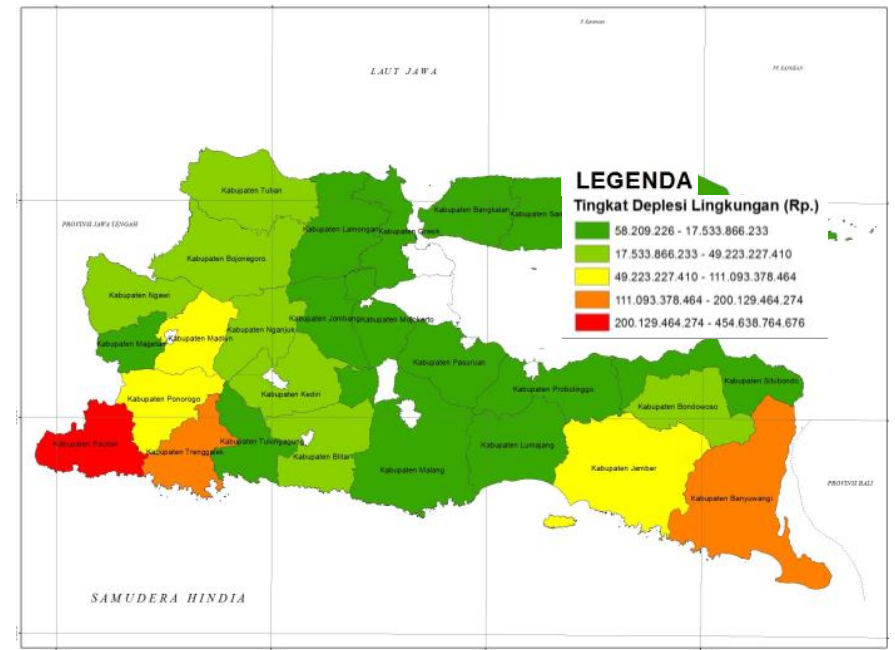

Gambar 1. Peta Tingkat Deplesi Lingkungan di Jawa Timur tahun 2015.

Berdasarkan hasil perhitungan pada Tabel 1 , nilai deplesi lingkungan di Jawa Timur tertinggi pada tahun 2015 terdapat di Kabupaten Pacitan sebesar Rp 454 Miliar, sementara nilai terbesar terdapat di Kabupaten Pamekasan sebesar Rp 58 Juta. Tinggi dan rendahnya nilai deplesi lingkungan dipengaruhi oleh tinggi dan rendahnya jumlah produksi kayu di kabupaten tersebut.

Selain itu, didapatan total nilai deplesi lingkungan di Jawa Timur pada tahun 2015 adalah sebesar Rp 1,46 Triliun. Deplesi sendiri termasuk diperhitungkan sebagai nilai tambah dalam kontribusi subsektor kehutanan pada PDRB. Padahal, penyusutan yang terjadi merugikan lingkungan, sehingga seharusnya sebagai pengurangan. Selain itu, nilai penyusutan ini tidak didukung dengan adanya dana reboisasi di setiap kabupaten di Jawa Timur.

\section{B. Laju Deplesi Lingkungan Subsektor Kehutanan di Jawa Timur}

Laju deplesi atau penyusutan menggambarkan besarnya sumber daya alam yang digunakan untuk memenuhi kebutuhan perekonomian sebagai modal yang harus dikeluarkan dalam pembangunan. Oleh sebab itu, selain mengestimasi nilai deplesi lingkungan subsektor kehutanan namun juga mengestimasi laju deplesi lingkungannya. 
Tabel 2.

Rata-Rata Laju Deplesi Lingkungan Subsektor Kehutanan di Jawa Timur tahun 2011-2015 (\%)

\begin{tabular}{|c|c|c|}
\hline No. & Kabupaten & Rata-Rata Laju Deplesi \\
\hline 1. & Kab. Pacitan & 13.69 \\
\hline 2. & Kab. Ponorogo & 122.49 \\
\hline 3. & Kab. Trenggalek & 1005.97 \\
\hline 4. & Kab. Tulungagung & 442.59 \\
\hline 5. & Kab. Blitar & 49.53 \\
\hline 6. & Kab. Kediri & 575.45 \\
\hline 7. & Kab. Malang & 16.05 \\
\hline 8. & Kab. Lumajang & -18.72 \\
\hline 9. & Kab. Jember & 36.01 \\
\hline 10. & Kab. Banyuwangi & 23.27 \\
\hline 11. & Kab. Bondowoso & 90.37 \\
\hline 12. & Kab. Situbondo & 40.89 \\
\hline 13. & Kab. Probolinggo & -9.52 \\
\hline 14. & Kab. Pasuruan & 33.58 \\
\hline 15. & Kab. Mojokerto & 570.80 \\
\hline 16. & Kab. Jombang & -4.44 \\
\hline 17. & Kab. Nganjuk & 4.38 \\
\hline 18. & Kab. Madiun & 11.78 \\
\hline 19. & Kab. Magetan & 304.14 \\
\hline 20. & Kab. Ngawi & 326.62 \\
\hline 21. & Kab. Bojonegoro & 5.92 \\
\hline 22. & Kab. Tuban & 27.73 \\
\hline 23. & Kab. Lamongan & -20.65 \\
\hline 24. & Kab. Gresik & 32.59 \\
\hline 25. & Kab. Bangkalan & 11.22 \\
\hline 26. & Kab. Sampang & 2.92 \\
\hline 27. & Kab. Pamekasan & 0.95 \\
\hline 28. & Kab. Sumenep & -17.74 \\
\hline
\end{tabular}

Sumber: Penulis, 2017

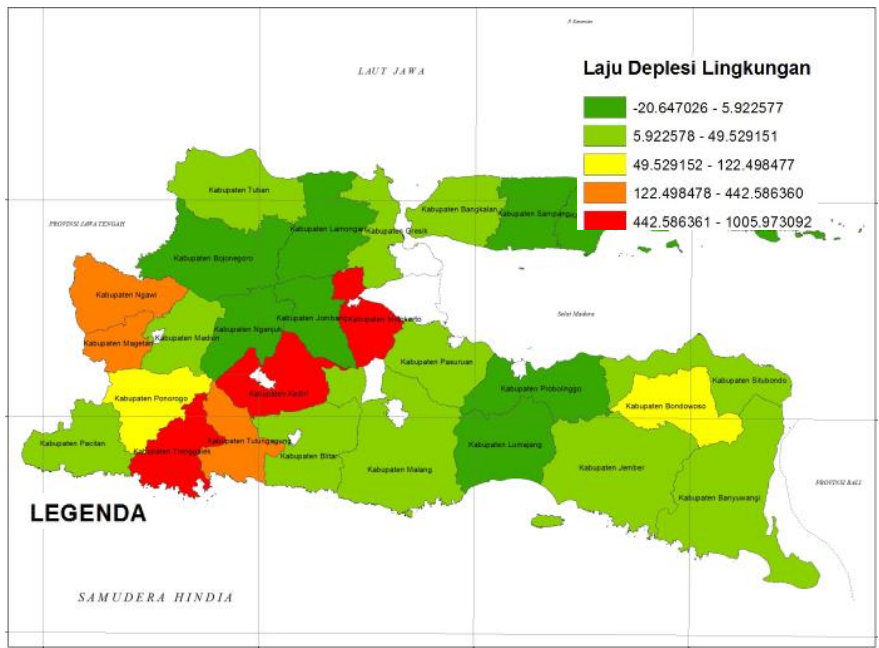

Gambar 2. Peta Rata-rata Laju Deplesi Lingkungan Subsektor di Jawa Timur tahun 2011-2015

Perhitungan laju deplesi terdapat nilai laju positif dan negatif, dimana laju dengan nilai positif merepresentasikan peningkatan nilai dibandingkan tahun sebelumnya, sementara laju dengan nilai negatif merepresentasikan sebaliknya. Laju dengan nilai negatif juga dapat didefinisikan sebagai adanya penanaman hutan di wilayah tersebut. Berdasarkan perhitungan laju deplesi beserta rata-rata laju deplesi, laju deplesi lingkungan tertinggi berada di Kabupaten Trenggalek yaitu naik sebesar $4187 \%$ dari tahun 2014 ke 2015 yang disebabkan oleh adanya kenaikan volume kayu yang ditebang secara drastis pada tahun 2015, yaitu sebesar $22.687 \mathrm{~m}^{3}$, sehingga nilai deplesi semakin besar. Sementara, laju deplesi terendah berada di Kabupaten Mojokerto yaitu menurun sebesar 97,6\% dari tahun 2012 ke 2013 yang disebabkan oleh adanya musim tanam di tahun 2012 sehingga aktifitas di subsektor kehutanan lebih ditekankan kepada penanaman dibandingkan penebangan.

Berdasarkan Tabel 2, rata-rata laju deplesi tertinggi berada di Kabupaten Trenggalek sebesar $1005.9 \%$ karena pada tahun2014 ke 2015, laju deplesi mengalami peningkatan sebesar $4187 \%$ yang disebabkan oleh adanya kenaikan volume kayu yang ditebang secara drastis pada tahun 2015, yaitu sebesar $22.687 \mathrm{~m}^{3}$. Sementara, rata-rata laju deplesi terendah berada di Kabupaten Lamongan sebesar $-20.6 \%$ dikarenakan pada tahun 2014 terdapat musim kemarau panjang sehingga volume produksi kayu turut menurun sebesar $72 \%$.

\section{Kuadran Nilai dan Laju Deplesi Lingkungan Subsektor Kehutanan di Jawa Timur}

Selain melihat nilai dan laju deplesi lingkungan, dilihat juga kuadran untuk mengetahui letak kabupaten berdasarkan karakteristiknya. Penentuan kuadran menggunakan software SPSS dengan alat analisis Multidimensional Scaling. Hasil dari Multidimensional Scaling berupa perceptual map yang akan dibagi lagi menjadi 4 (empat) kuadran seperti yang diilustrasikan pada gambar dibawah ini:

Derived Stimulus Configuration

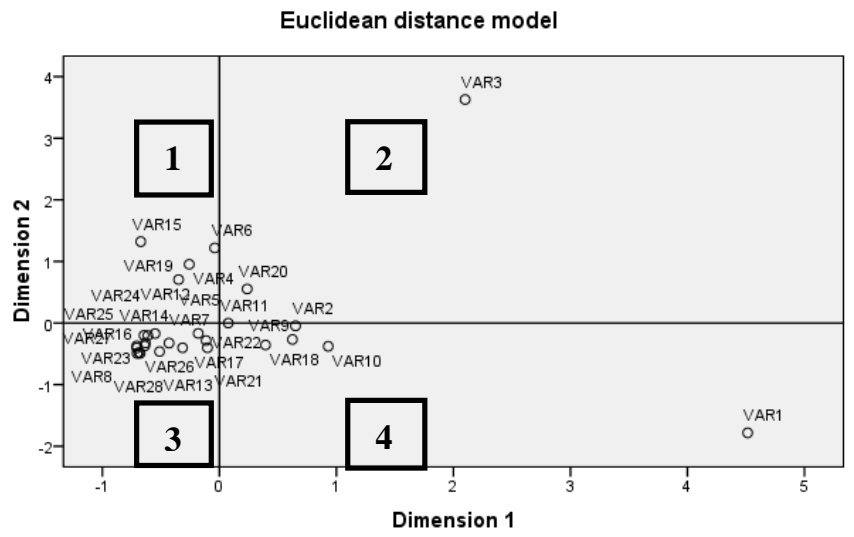

Gambar 3. Hasil Perceptual Map Nilai dan Laju Deplesi Lingkungan Setiap Kabupaten di Jawa Timur

Berdasarkan hasil perceptual map, terdapat tiga pengelompokkan dimana Variabel 1 (Kabupaten Pacitan) terletak jauh diantara variabel lainnya karena memiliki nilai PDRB paling rendah diantara kabupaten lainnya, sementara Variabel 3 (Kabupaten Trenggalek) juga terpisah dari variabel lainnya karena memiliki nilai laju deplesi paling tinggi diantara kabupaten lain di Jawa Timur. Sehingga dapat disimpulkan bahwa sumbu $\mathrm{X}$ merupakan nilai deplesi dan sumbu Y merupakan laju deplesi.

Kuadran 1 terdiri dari Kabupaten Tulungagung, Kediri, Mojokerto, serta Magetan. Kabupaten-kabupaten ini memiliki ciri laju deplesi diatas rata-rata dan nilai deplesi dibawah ratarata. Sementara, kuadran 2 terdiri dari Kabupaten Trenggalek, Bondowoso dan Ngawi yang memiliki nilai laju dan deplesi diatas rata-rata. Hal tersebut menandakan bahwa terjadi 
pengikisan hutan yang parah pada ketiga kabupaten tersebut sehingga diperlukan adanya kegiatan reboisasi yang rutin agar lahan hutan tidak terkikis habis.

Kuadran 3 terdiri dari Kabupaten Banyuwangi, Madiun, Jember, serta Tuban yang memiliki ciri laju deplesi dibawah rata-rata sementara nilai deplesi diatas rata-rata. Sementara outlier yang masih termasuk kuadran 3 adalah Kabupaten Pacitan memiliki ciri nilai deplesi paling rendah sementara laju deplesi dibawah rata-rata.

Kuadran 4 yang terdiri dari Kabupaten Ponorogo, Blitar, Malang, Lumajang, Situbondo, Probolinggo, Pasuruan, Jombang, Nganjuk, Bojonegoro, Lamongan, Gresik, Bangkalan, Sampang, Pamekasan dan Sumenep. Kabupatenkabupaten tersebut memiliki ciri nilai deplesi dan laju deplesi dibawah rata-rata.

Sehingga dapat disimpulkan bahwa lebih dari setengah jumlah kabupaten di Jawa Timur memiliki karakteristik deplesi yang tergolong rendah, dimana nilai deplesi pada tahun 2015 serta laju deplesi pada tahun 2011-2015 dibawah rata-rata. Meski demikian, tetap diperlukan adanya kebijakan dari pemerintah mengenai pemanfaatan subsektor kehutanan agar keberlanjutannya terjaga hingga seterusnya.

\section{KESIMPULAN}

Hasil penelitian ini menunjukkan bahwa deplesi atau penyusutan sumber daya hutan terbesar yang terjadi di Jawa Timur pada tahun 2015 terdapat di Kabupaten Pacitan sebesar Rp 454,6 Miliar sementara nilai deplesi terendah terdapat di Kabupaten Pamekasan sebesar Rp 58 Juta. Faktor utama penyebab tinggi dan rendahnya nilai deplesi lingkungan adalah besarnya volume produksi kayu di masing-masing kabupaten di Jawa Timur.

Rata-rata laju deplesi pada tahun 2011-2015 tertinggi berada di Kabupaten Trenggalek sebesar $1005.9 \%$ yang disebabkan oleh adanya peningkatan volume produksi secara drastis pada tahun 2014 ke 2015. Sementara, rata-rata laju deplesi terendah berada di Kabupaten Lamongan sebesar $20.6 \%$ karena adanya penurunan volume produksi kayu sebesar 72\% di tahun 2014.

Berdasarkan kuadran nilai dan rata-rata laju deplesi setiap kabupaten di Jawa Timur, diketahui bahwa karakteristik mayoritas kabupatennya adalah memiliki deplesi yang tergolong rendah. Namun demikian, masih terdapat 3 kabupaten pada kuadran 2 (Kabupaten Trenggalek, Bondowoso, dan Ngawi) yang memiliki ciri deplesi yang sangat tinggi.

Hasil penelitian ini dapat dijadikan sebagai bahan pertimbangan untuk perhitungan PDRB Hijau di Jawa Timur. Selain itu, dapat juga dijadikan sebagai rekomendasi untuk menyusun kebijakan terkait implementasi konsep perekonomian yang hijau, yaitu turut mempertimbangkan aspek lingkungan dan mencegah terjadinya eksternalitas negatif dari aktivitas ekonomi.

\section{DAFTAR PUSTAKA}

[1] Badan Perencanaan dan Pembangunan Provinsi Jawa Timur, Rencana Pembangunan Jangka Panjang Daerah Provinsi Jawa Timur Tahun 2005-2025. Surabaya, 2009.

[2] Pemerintah Provinsi Jawa Timur, Rencana Aksi Daerah untuk Penurunan Emisi Gas Rumah Kaca (RAD-GRK). Surabaya: Pemprov Jawa Timur, 2012.

[3] Kementrian Lingkungan Hidup dan Kehutanan, Statistik Kementrian Lingkungan Hidup dan Kehutanan Tahun 2014. Jakarta: Kementrian Lingkungan Hidup dan Kehutanan, 2015.

[4] Dinas Kehutanan Provinsi Jawa Timur, Statistik Dinas Kehutanan Tahun 2011. Surabaya: Dishut Jawa Timur, 2012.

[5] WALHI, "Walhi: 608.913 hektare lahan hutan Jatim kritis akibat eksploitasi tambang," 2016. [Online]. Available: http://walhijatim.or.id/2016/06/walhi-608-913-hektare-lahan-hutanjatim-kritis-akibat-eksploitasi-tambang/.

[6] E. Roslinda, "PDRB Hijau Sektor Kehutanan Melalui Pendekatan Nilai Ekonomi Jasa Lingkungan,” Universitas Tanjungpura, 2014.

[7] Dinas Kehutanan Provinsi Jawa Timur, Rencana Strategis Dinas Kehutanan Jawa Timur Provinsi Jawa Timur (2009-2014). Surabaya: Dishut Jawa Timur, 2009.

[8] Badan Perencanaan Pembangunan Nasional, Sintesis: Mewujudkan Pertumbuhan Ekonomi Hijau untuk Indonesia yang Sejahtera. Jakarta: Program Pertumbuhan Ekonomi Hijau Pemerintah Indonesia-GGGI. 2015.

[9] W. Yuanzhou, H., Shuirong, Valuation and Green Accounting of Tropical Forest Assets. Beijing: International Tropical Timber Organization, 2008.

[10] F. Hanurawan, "Pendekatan Positivistik, Interpretif, Kritis dalam Penelitian Pendidikan," J. Teor. dan Prakt. Penelit. IKIP Malang, vol. 10, pp. 3-16, 1998.

[11] M. Suparmoko, Ekonomi Sumber Daya Alam dan Lingkungan: Suatu Pendekatan Teoritis. Yogyakarta: BPFE, 2008. 